\title{
Modelling of an innovative and autonomous micro-grid based on a biomass - solar PV hybrid power system.
}

\author{
Michela Costa $^{1 *}$, Gaia Martoriello ${ }^{1,2}$, Raffaele Tuccillo ${ }^{2}$ \\ ${ }^{1}$ Istituto Motori, CNR, Viale Marconi, 4 - 80125 Naples, Italy \\ ${ }^{2}$ University of Naples Federico II, Department of Industrial Engineering, Via Claudio, 21 - 80125 Naples, Italy
}

\begin{abstract}
Micro-Combined heat and power (m-CHP) systems fuelled by renewables, such as residual biomasses, are today of great interest to produce energy in an efficient and green way. The aim of the present work is to develop a numerical model of a hybrid energy system including a biomass powered $\mathrm{m}$-CHP unit based on gasification and coupled with solar photovoltaic (PV) modules and to an electrical storage device, able to provide energy to remote areas. Main advantages of the considered configuration are its ultra-low environmental impact and just its autonomous operation by local resources. The developed unsteady multiphysical model accounts for the main plant components, namely the syngas powered engine, the PV panels and the battery, as well for a dynamic use of the produced energy. Main features of the adopted schematization of the actual system rely on the proper description of syngas combustion, that takes into account the extreme difficulty of working with a non-conventional gas, and on a PID control that is considered for energy flow management to meet the electrical demand curve. The PV panel current is calculated through an ad-hoc function that reads, at any given time, actual solar irradiance data in the city of Naples, Italy, the battery voltage and the main parameters of the PV module. The battery, with a voltage of $48 \mathrm{~V}$ and a capacity of $100 \mathrm{kWh}$, is modelled as an equivalent circuit with its proper State of Charge (SoC) versus Open Circuit Voltage (OCV) curve. The voltage response to a current at a particular SoC and temperature are calculated. This dynamic modelling permits the optimal control of the whole system to meet the electrical and thermal user's demand and also to better design any possible change in the storage or PV size to meet specific real uses of the produced energy.
\end{abstract}

\section{Introduction}

The use of a fully renewable energy mix is perfectly in line with the series of compulsory indications and regulations established in Europe, as well as over the whole planet, to counteract harmful effects of climate change on human living and wellness. In particular, the integration of solar photovoltaic (PV) and biomassbased micro-cogeneration systems, either connected to the low voltage national grid or in an off-grid configuration, could be particularly advantageous if locally available renewable sources are involved in a combined production of decentralized electricity and also heat, so resulting directly accessible at the consumer level [1]. A joint use of cogeneration (combined heat and power - CHP) and solar PV energy conversion, together with storage systems, have proved being interesting and efficient if compared to the traditional access to the power grid, to avoid dissipation related to the distance from the generator [2].

In areas with abundant solar radiation, $\mathrm{PV}$ has a great potential although it is obviously subjected to the discontinuous nature of the energy source. Biomass powered generation could fulfil this lack by providing a more continuous energy supply in an environmentalfriendly way. The energy balancing problem is indeed one of the main challenges, more generally when different renewable energy generation systems are involved and for an effective application of hybrid systems (possibly including storage) to micro-grids. A correct energy management is compulsory to avoid inefficiencies, minimize the total operation cost and ensure durable energy storage equipment. A correct sizing of the electric battery capacity could ensure less fluctuations and a stronger ability to peak shaving, thus realizing better long-term economic performances [3]. To give some examples, a parametric techno-economic

\footnotetext{
* Corresponding author: m.costa@im.cnr.it
} 
analysis of a micro-grid system involving PV and a battery system was proposed by Zhang et al. [4] under different electricity tariffs. The cost of electricity of the PV system increases with the battery size, whereas it reduces with the increase of the plant size. Singh et al. [5] presented a feasibility study of a hybrid PV-wind generation system along with biomass and storage. The system was shown to be reliable and economic, thanks to the development of a numerical model used to find the optimal size of the battery. Another feasibility study was proposed by Ma et al. [6] who showed how an existing diesel generation could be fully replaced by a $100 \%$ renewable energy generation mix, through an optimization of sizing of both wind and solar generation. Deterministic constrained optimization was used by Zheng et al. [7] to design a biomass-integrated microgrid that employed CHP with electric storage. A correct modelling of the micro-grid operation, indeed, was useful to determine major risk factors of different system designs.

When dealing with biomass it is to be considered that this renewable source could be converted into energy along two main paths: thermochemical and biochemical processes. Among them, thermochemical processes have higher conversion efficiency than biological ones. Thermochemical processes include direct combustion, torrefaction, pyrolysis, gasification, and hydrothermal liquefaction. Typical applications for biomass-fuelled CHP over the micro-scale of power (mCHP) use direct combustion technologies, but those based instead on gasification have higher electrical efficiency and lower environmental impact. Syngas deriving from biomass gasification is indeed a promising alternative fuel, especially if used in internal combustion engines, machines that are flexible and suitable to frequent start and stop procedures with low particulate matter (PM) emissions [8]. However, there are still very few commercialized $\mathrm{m}-\mathrm{CHP}$ units based on this technology and yet no paper exists in the literature treating micro-grids involving a mix of $\mathrm{PV}$ and this technology.

In the present paper, a numerical multi-physical model was developed through the use of the commercial software AVL CRUISE-M ${ }^{\circledR}$ to show a typical application of a hybrid energy system including a biomass-fueled m-CHP unit, based on gasification, and solar PV modules. The properly developed model, validated on available experimental measurement of the mCHP system performances, was able to perform unsteady simulations, by considering the syngas powered engine and the variable nature of solar source for two different scenarios:

- on-grid scenario: the solar PV modules are initially used to charge a $2.7 \mathrm{kWh}$ battery, which in turn serves to switch on the internal combustion engine (ICE). Once started, the ICE and the PV components produce energy sent to the national grid.

- off-grid scenario: Once started the PV and ICE modules meet a dynamic electric load with the excess energy stored in a $100 \mathrm{kWh}$ battery.

The performed simulations are representative of two different uses of the hybrid energy system, and clearly are relevant to different environments or end user kinds.
They are chosen just to explore advantages and limits of the two configurations and are used to show the potentiality of numerical modelling in micro-grid management. The same modelled components do not limit the discussion, as they are demonstrative of some design choices, but the model has indeed a general character and can be easily adapted to numerically reproduce other related conditions.

\section{Development of the micro-grid model}

A numerical simulation model for hybrid generation and storage systems is here developed by using the AVL CRUISE-M ${ }^{\circledR}$ software, a commercial multidisciplinary system simulation tool that allows combining various sources, storage devices and users to analyse in a "digital twin" the actual behaviour of distributed energy systems.

The European Commission (EC) guidelines towards current energy and climate change policy goals of the so-called "Clean Energy for all Europeans", indeed, surely provide new opportunities to all users and customers of the future energy systems, but also bring new constraints, especially for distribution systems operators. This fact, combined with the variability and uncertainty of renewable energy sources, as well as the installation of new technologies such as energy storage systems, poses new challenges to distributed plant design, monitoring and operation. The here developed model, therefore, is here presented as a tool able to provide a support to decision making, check operation capability under various loads or to define the control strategy of distributed energy systems in micro-grids under various plant configurations.

The chosen case study is based on sole renewables, as it considers energy generation by a biomass powered m-CHP system, namely the commercial CMD ECO20X manufactured by the Company Costruzioni Motori Diesel S.p.A., whose complete description is reported in ref. [9], and by solar energy through PV panels. The micro-cogeneration unit is composed by a downdraft gasifier, syngas cleaning devices, an ICE and a waste heat recovery circuit. Fig. 1 shows a scheme of the developed model, in which four sub-systems are visible: the m-CHP unit, the Battery, a PV solar module, a Control system. The yellow and green line represent, respectively, electric and mechanic connections, while unshown connection are given through data buses.

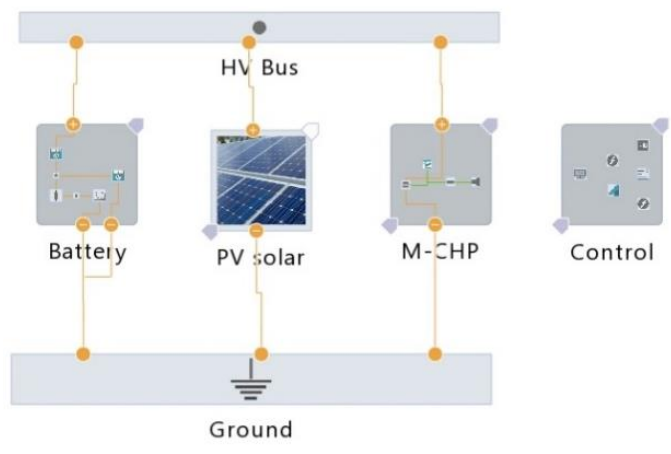

Figure 1. Layout of the developed multi-physical model of the hybrid micro-grid. 
A map-based engine (MBE) was used to model the performance of the spark-ignition engine fuelled by syngas. The MBE is a component capable of simulating the basics of internal combustion reciprocating engines, by following a "black box" approach, by handling maps and characteristics to be interpolated in order to capture the physical behaviour of the ICE. The system is designed to process ligneous biomass, chipped or briquetted, with a maximum humidity of $20 \%$. Up to 20 $\mathrm{kW}$ electrical power and $40 \mathrm{~kW}$ thermal power are delivered to the user.

The MBE performance is here parametrized by introducing three different maps along with engine data and general properties, i.e. number of cylinders, engine displacement, engine inertia, fuel composition and properties.

The required maps, are:

-Motoring torque: 1-D speed dependent characteristics that represent the resistance torque of the MBE when the plant load is null.

-Full load torque: 1-D speed dependent characteristics that define the maximum possible steady state torque of the plant.

-Fuel Consumption Map: 2-D characteristic map in which the mass flow fuel consumption rate is related to the correspondent engine speed and torque.

In order to acquire the two 1-D speed dependent characteristics and the fuel consumption map that is shown in Fig. 2, a validated 0-1D model was used. The model was developed within the GT-Suite environment and validated on the ground of real engine data under various syngas compositions. Its detailed description is given in ref. [9],

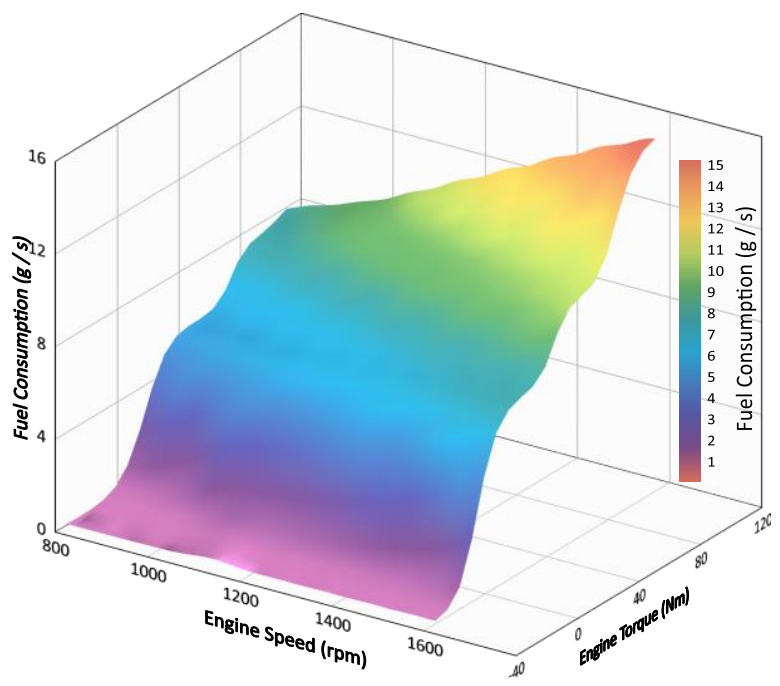

Figure 2. Fuel consumption map (g/s) vs speed (rpm) and torque $(\mathrm{Nm})$.

Table 1 reports the syngas properties that were specified in the MBE.

The MBE is connected to a flange through a crankshaft that gives it the initial rotational speed; this is also connected to the electric motor (E-Motor 1). The model of the electric machine refers to both electric motors and generators by using a simple map-based approach. Both operation modes can be defined separately for positive and negative speeds. For each quadrant, the maximum full load torque characteristics can be introduced as voltage and speed dependent maps. For motor quadrants, speed and torque must have the same sign, for generator they must have opposite signs. In this study, only two quadrants were needed: Q1 and $\mathrm{Q} 4$, since motor and generator modes have the same direction of rotation while a negative torque is typical of generator operation. The full load torque maps at $48 \mathrm{~V}$ of voltage are shown in Fig. 3.

The battery model is based upon an equivalent electrical circuit, and it is able to predict the voltage response to a current at a particular state of charge (SoC) and at a given temperature. A controlled voltage source and an Ohmic resistance were used to describe the instantaneous voltage response to a current input. The state of charge (SoC) dependent open circuit voltage (OCV) curve is calculated through the following equation:

$$
V_{O C}=a_{1} e^{b_{1} S O C}+a_{2} e^{b_{2} S O C}+c S O C^{2},
$$

where $a_{1}, a_{2}, b_{1}$ and $b_{2}$ and $c$ are appropriate corrective factors [10].

Table 1. Syngas properties

\begin{tabular}{|c|c|c|}
\hline Properties & Unit & Value \\
\hline $\mathrm{H} 2$ & $\mathrm{~mol} / \mathrm{mol}$ & 0.0118 \\
\hline $\mathrm{CO}$ & $\mathrm{mol} / \mathrm{mol}$ & 0.2002 \\
\hline $\mathrm{CH} 4$ & $\mathrm{~mol} / \mathrm{mol}$ & 0.0114 \\
\hline $\mathrm{CO} 2$ & $\mathrm{~mol} / \mathrm{mol}$ & 0.149 \\
\hline $\mathrm{C} 2 \mathrm{H} 6$ & $\mathrm{~mol} / \mathrm{mol}$ & 0.0046 \\
\hline $\mathrm{N} 2$ & $\mathrm{~mol} / \mathrm{mol}$ & $0.6021 \%$ \\
\hline $\mathrm{H} 2 \mathrm{O}$ & $\mathrm{mol} / \mathrm{mol}$ & $0.0209 \%$ \\
\hline$\alpha \mathrm{st}$ & - & 1.185 \\
\hline $\mathrm{LHV}$ & $\mathrm{MJ} / \mathrm{kg}$ & 4.23 \\
\hline
\end{tabular}

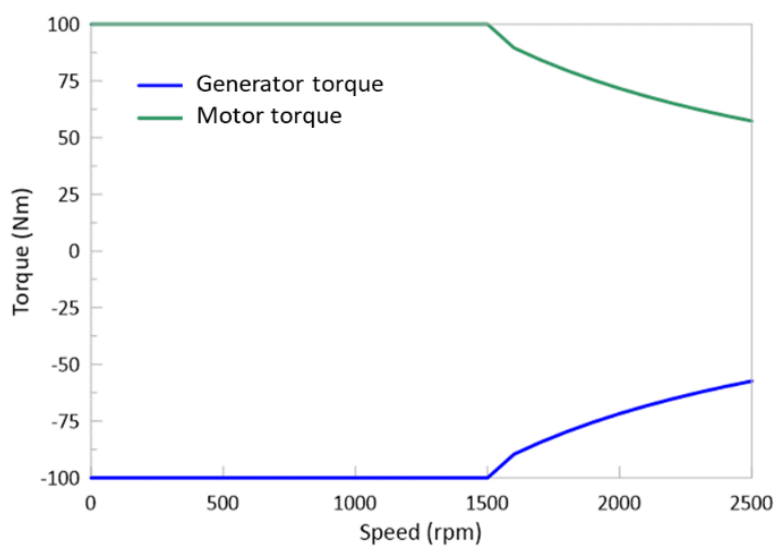

Figure 3. E-Motor maximum full-load torque characteristic map at $48 \mathrm{~V}$.

The electrical power generation in a PV based system is possible thanks to the electric potential difference between two thin silicon sheets under the exposure to solar irradiance. Each PV panel is formed by several modules, which can be arranged in arrays (several modules in series) and in fields (several arrays in parallel). Each module is characterized by a shortcircuit current (Isc), an open circuit voltage (Voc) and a Voltage-Current characteristic curve (VI), defined for 
$1000 \mathrm{~W} / \mathrm{m}^{2}$ of solar irradiance and $25^{\circ} \mathrm{C}$ of ambient temperature. This curve uniquely identifies the point of maximum power (PMPP). However, the energy actually produced must be reduced by taking into consideration two efficiencies:

- the module efficiency ( $\left.\eta_{\text {module }}\right)$, defining heating and module degradation losses;

- the balance of point efficiency $\left(\eta_{\text {BOP }}\right)$, i.e. energy losses due to auxiliary devices, inverter, etc., typically around 0.78 .

Table 2 reports the main PV panel parameters considered in this study. Fig. 6 shows the layout of the PV solar sub-system. At each simulation step, the subsystem reads the input solar irradiance map $\left(G_{a c t}\right)$ and current is calculated through equation (2):

$$
I=\frac{P_{P V}}{V}
$$

where $\mathrm{I}$ is current, $\mathrm{V}$ is the voltage and $\mathrm{P}_{\mathrm{PV}}$ is the actual generated electrical power of the PV system, defined by the following equation:

$$
P_{P V}=\frac{\left(P_{M P P} * G_{\text {act }} * A_{\text {mod }} * n_{\text {array }} * n_{\text {field }}\right)}{G_{\text {standard }}} .
$$

\begin{tabular}{|c|c|c|}
\hline Properties & Unit & Value \\
\hline PMPP $_{\text {MP }}$ & $\mathrm{W}$ & 185 \\
\hline $\mathrm{V}_{\mathrm{MPP}}$ & $\mathrm{V}$ & 36.4 \\
\hline IMPP & $\mathrm{A}$ & 5.09 \\
\hline $\begin{array}{c}\text { Number of } \\
\text { modules }\end{array}$ & - & 108 \\
\hline $\begin{array}{c}\text { Number of } \\
\text { modules per string }\end{array}$ & - & 12 \\
\hline $\begin{array}{c}\text { Number of strings } \\
\text { in each array }\end{array}$ & - & 3 \\
\hline $\begin{array}{c}\text { Number of fields } \\
\left(\mathrm{n}_{\text {field }}\right)\end{array}$ & - & 3 \\
\hline $\begin{array}{c}\text { Standard solar } \\
\text { radiance }\left(\mathrm{G}_{\text {standard }}\right)\end{array}$ & $\mathrm{W} / \mathrm{m}^{2}$ & 1000 \\
\hline$\eta_{\mathrm{BOP}}$ & - & 0.78 \\
\hline$\eta_{\text {modulen }}$ & - & Up to 0.145 \\
\hline $\mathrm{PPV}$ max $_{2}$ & $\mathrm{~kW}$ & 20 \\
\hline
\end{tabular}

Table 2. PV panel main properties [11].

The control sub-system was modelled differently depending upon two different possible scenarios:

- on-grid configuration: the m-CHP unit switches on thanks to the battery, charged through solar energy. The solar PV modules and the m-CHP system are then connected to the national grid. Operation of $\mathrm{m}-\mathrm{CHP}$ is always at full-load.

- off-grid configuration: the m-CHP unit and the Solar PV modules follow an imposed electrical load and the excess electrical energy is stored into the battery. The m-CHP unit is hypothesized already in service.

For both scenarios, a PID controller was proposed for the MBE to define the desired power output, in order to account for different load requirements. The PID controller acts on the MBE desired torque to achieve a proper electrical power. Proper components were used for user-defined functions, through the programming language $\mathrm{C}$. The load function defines the coupling with the Electric Motor, while the PID control is used to define the desired output power. The multi-column map "ICE switch" defines the instant of switching in of the MBE. The monitor component is able to control values of component input values during the simulation.

\section{Results}

For both scenarios, the simulation of one week at the end of January in the city of Naples, Italy, was performed. Solar irradiance is shown in Fig. 4. The start of the analysed period coincides with the 00:00 hour of the first day. The integration step was set at $5 \mathrm{~s}$.

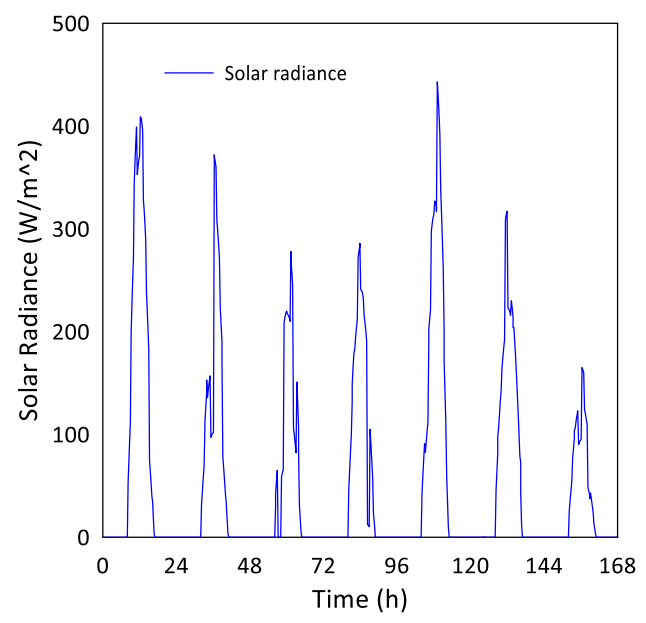

Figure 4. Solar radiance of the city of Naples (Italy) during the first week of January.

Table 3. Main parameters of the selected battery.

\begin{tabular}{|c|c|c|}
\hline Properties & $\begin{array}{c}\text { On-grid } \\
\text { scenario }\end{array}$ & $\begin{array}{c}\text { Off-grid } \\
\text { scenario }\end{array}$ \\
\hline Nominal voltage $(\mathrm{V})$ & 12 & 48 \\
\hline Nominal capacity $(\mathrm{Ah})$ & 225 & 2083 \\
\hline Discharge voltage range $(\mathrm{V})$ & $8-17$ & $45-54$ \\
\hline Working temperature $\left({ }^{\circ} \mathrm{C}\right)$ & $10-50$ & $10-50$ \\
\hline
\end{tabular}

Table 3 reports the main parameters of two selected batteries. For the on-grid scenario, the battery was chosen to be able to the recharge through the connection with the PV panels and to switch on the m-CHP system, while in the off-grid scenario, the battery is dimensioned to be able both to store the excess electrical energy and to provide the extra electrical power, if the requested electrical load gets higher than the produced one. The next two paragraphs report the main results of the simulations.

\subsection{On-grid configuration}

Fig. 5 shows the dispatched electrical power and Fig. 6 the battery SoC. Positive values of the battery flux indicate the electrical power delivered, while negative values indicate received electrical power. For a better visualization of the SoC, only the first 20 hours are shown in Fig. 6. During the first 10 hours, the PV module charges the battery to $100 \%$, so the m-CHP can start with the energy from the storage system, whose 
SoC is so reduced to $55 \%$. The first 8.9 hours, solar irradiance is null due to the time of start assumed at the hour 00:00 of the first day. Indeed, battery charges in about 1.2 hour. Then, after the mCHP start, it is recharged till $100 \%$ again through solar irradiance. From $11.30 \mathrm{~h}$ to the end of simulation, solar PV and $\mathrm{m}$ CHP at maximum load $(16 \mathrm{~kW})$ both dispatch energy to the national grid.

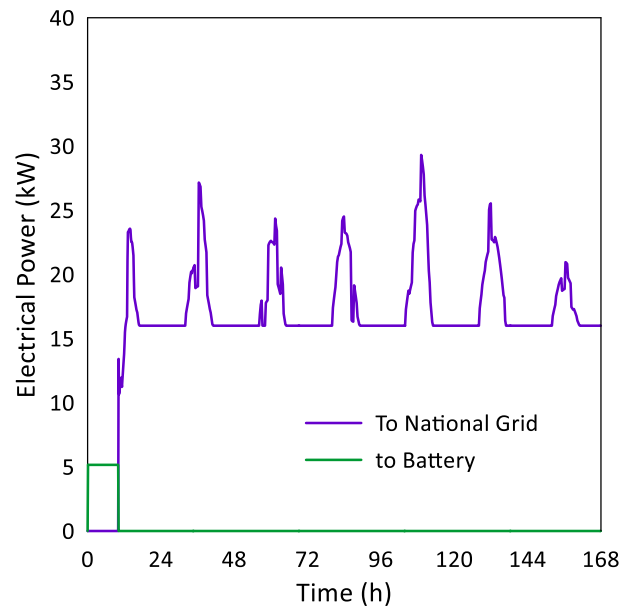

Figure 5. Dispatched electrical power.

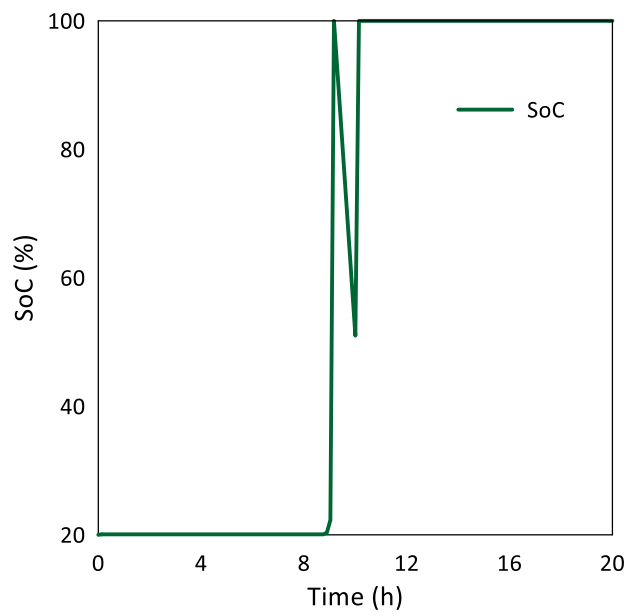

Figure 6. SoC of the proposed battery (on-grid scenario).

\subsection{Off-grid configuration scenario}

The assumed load profile is a basic weekly demand of a small industry with a daily average of $13 \mathrm{kWh}$. Fig. 7 shows the selected electrical load.

A basic energy dispatch strategy is used, whose operation principle flow chart is depicted in Fig. 8. The micro-grid is hypothesized to be not connected to the national grid, so that the excess electrical energy cannot be sold. Fig. 9 shows the results of the calculation: the dispatched electrical power by the solar PV, the m-CHP unit and the battery are represented.

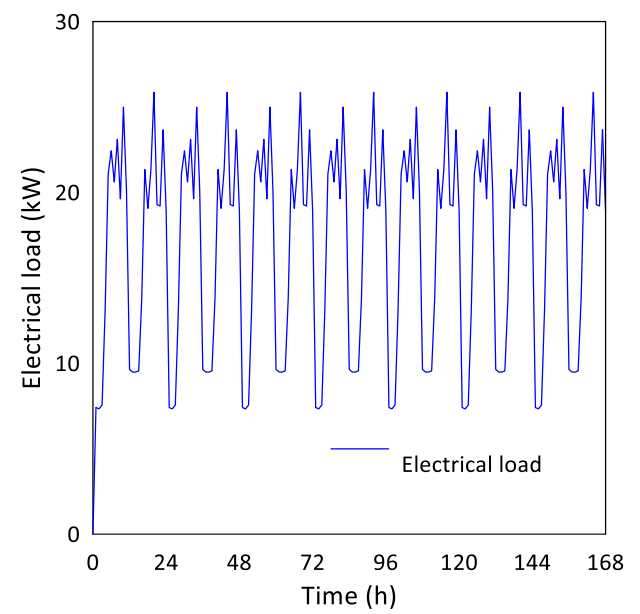

Figure 7. Electrical load.

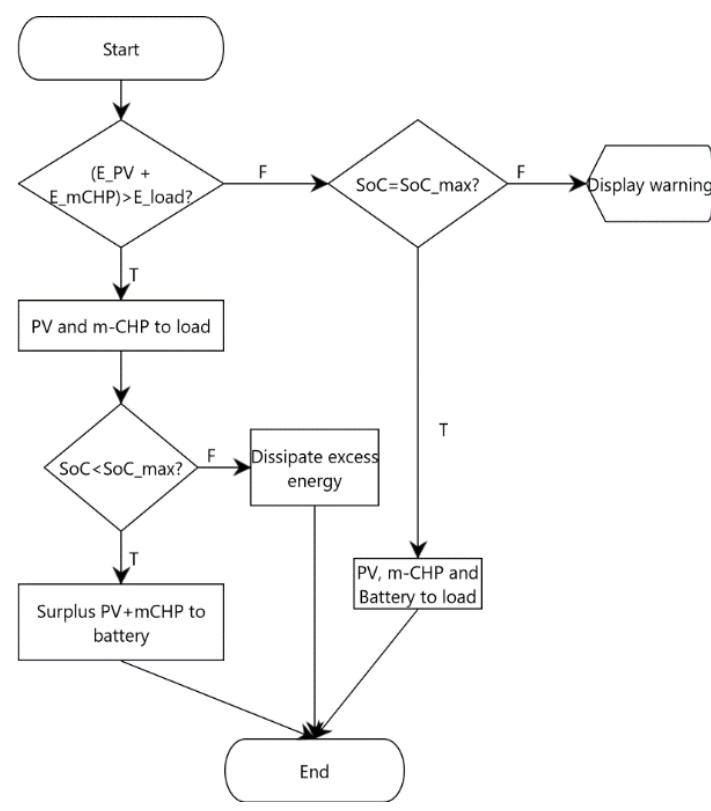

Figure 8. Energy dispatch flow chart.

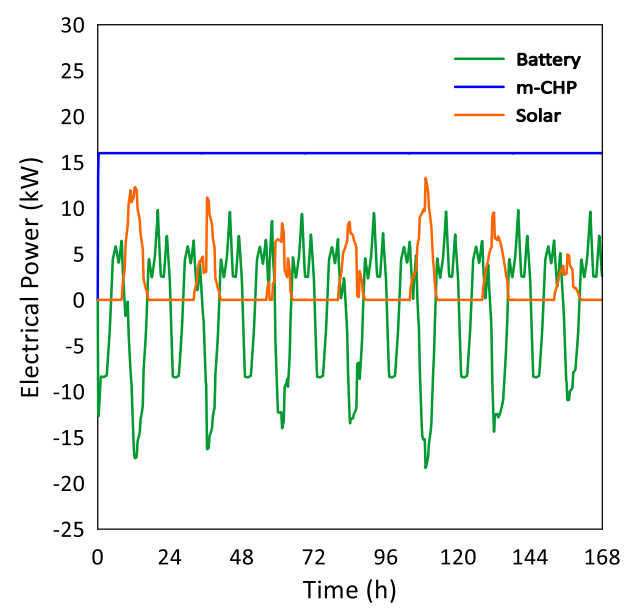

Figure 9. Dispatched electrical power. 


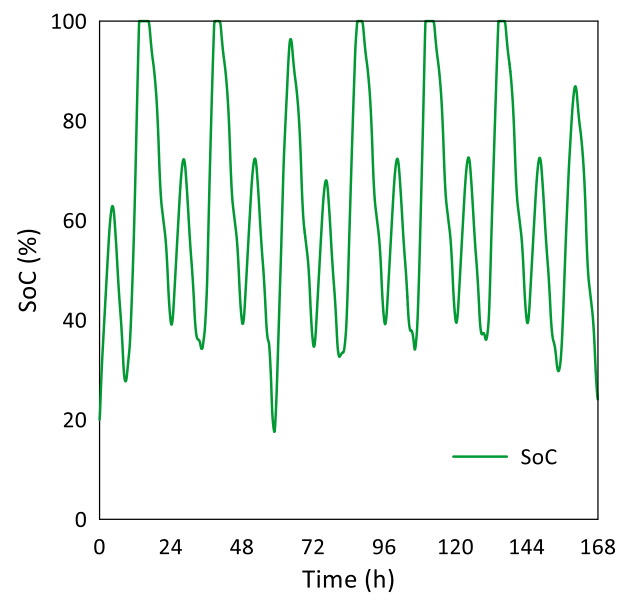

Figure 10. SoC of the proposed battery (off-grid scenario).

Fig. 10 depicts the SoC of the battery in the off-grid scenario. It is important to point out that the battery SoC should never be lower than $20 \%$ and should not be at $100 \%$ for long times, to preserve its component life. The SoC ranges between $30-80 \%$. The size of the battery, therefore, is well calibrated to the proposed application. Analogous dynamic simulations could be performed through the here developed model to comply with different energy demands.

\section{Conclusion}

A hybrid photovoltaic-m-CHP-battery system is simulated in two different scenarios, namely in an ongrid and an off-grid configuration to analyse the performance of the served micro-grid.

A comprehensive model was developed and a dynamic simulation was performed within the CRUISE$M \circledR$ environment. The model is shown to be a useful tool for the evaluation of the behaviour of the plant.

In both cases, the multi-physical model is shown to be able to show the energy fluxes at the battery, the mCHP unit and the solar PV, so to solve any balancing problem and define a logical dispatch control for the produced energy. With a fast response, the correct size of the battery and PV panels can be designed without possible waste of money due to oversizing.

The on-grid configuration is the best answer in terms of reliability and consistency. In case of failure of any power system, the national grid will share the load, avoiding blackouts. The grid covers a large number of consumers, so the fluctuation of load demand of a grid is much less than that of a single generating plant. In the on-grid configuration the battery could be smaller than off-grid, since no storage is needed except for the start phase. The off-grid configuration may allow remote countries to be prosumers of energy, namely producers and consumers at the same time, so to avoid insulation or resorting to expensive grid extensions. A correct size of the battery capacity is needed to ensure lower fluctuations and a stronger ability to peak shaving. The $100 \%$ renewable energy system is shown to be able to replace any existing technology.

A next step of the present activity for the future is the implementation of the model within parametric analyses and optimization problems coupled with techno-economic analyses that will provide the optimal solution and the correct balance between battery and solar PV sizing. Different syngas compositions and different tables of solar radiance based on the effective location of the system could be easily implemented in the proposed model.

\section{References}

[1] S. Martinez, G. Michaux, P. Salagnac, e J.-L. Bouvier, «Micro-combined heat and power systems (micro-CHP) based on renewable energy sources», Energy Convers. Manag., vol. 154, pagg. 262-285, 2017.

[2] J. Li et al., «Analysis of a new design of the hybrid energy storage system used in the residential mCHP systems», Appl. Energy, vol. 187, pagg. 169179, 2017.

[3] C. Wang, Y. Liu, X. Li, L. Guo, L. Qiao, e H. Lu, «Energy management system for stand-alone diesel-wind-biomass microgrid with energy storage system», Energy, vol. 97, pagg. 90-104, 2016.

[4] Y. Zhang, T. Ma, P. E. Campana, Y. Yamaguchi, e Y. Dai, «A techno-economic sizing method for grid-connected household photovoltaic battery systems», Appl. Energy, vol. 269, pag. 115106, 2020.

[5] S. Singh, M. Singh, e S. C. Kaushik, «Feasibility study of an islanded microgrid in rural area consisting of PV, wind, biomass and battery energy storage system», Energy Convers. Manag., vol. 128, pagg. 178-190, 2016.

[6] T. Ma, H. Yang, e L. Lu, «A feasibility study of a stand-alone hybrid solar-wind-battery system for a remote island», Appl. Energy, vol. 121, pagg. 149158, 2014.

[7] Y. Zheng, B. M. Jenkins, K. Kornbluth, e C. Træholt, "Optimization under uncertainty of a biomass-integrated renewable energy microgrid with energy storage», Renew. Energy, vol. 123, pagg. 204-217, 2018.

[8] Y. A. Situmorang, Z. Zhao, A. Yoshida, A. Abudula, e G. Guan, «Small-scale biomass gasification systems for power generation $(<200 \mathrm{~kW}$ class $)$ : A review», Renew. Sustain. Energy Rev., vol. 117, pag. 109486, 2020.

[9] M. Costa et al., «Model based optimization of the control strategy of a gasifier coupled with a spark ignition engine in a biomass powered cogeneration system», Appl. Therm. Eng., pag. 114083, 2019.

[10] R. Zhang et al., "A study on the open circuit voltage and state of charge characterization of high capacity lithium-ion battery under different temperature», Energies, vol. 11, n. 9, pag. 2408, 2018.

[11] F. Hosseini, B. M. Goortani, e M. Niroomand, «Instantaneous responses of on-grid PV plants to changes in environmental and weather conditions», Int. J. Renew. Energy Res., vol. 6, n. 4, pagg. 12961306, 2016. 